\title{
Effects of the Contamination of Atrazine and Pb on Soil Microbial Biomass Carbon
}

\author{
Baoshan Yang ${ }^{1,2}$, Qinglin Chen ${ }^{1,2}$, Hui Wang ${ }^{* 1,2}$ \\ ${ }^{1}$ College of Resources and Environment, University of Jinan, Jinan 250022, China; \\ ${ }^{2}$ Shandong Provincial Engineering Research Center for Ecological Carbon Sink and Capture Utilization, Jinan 250022, China \\ *Corresponding author:hwang_118@163.com
}

\begin{abstract}
Herbicides are widely used in modern agriculture systems and vehicle exhaust significant emissions caused $\mathbf{P b}$ contamination. After entering the soil ecosystem it will produce complex ecological effects, which cause certain effects on soil microbial biomass and biological activity. Choose common herbicide of soil contaminants $\mathrm{Pb}$ and atrazine, under artificial controlled conditions, using fumigation extraction method, explore the impact of combined pollution of different concentrations of $\mathrm{Pb}$ and atrazine on soil microbial biomass carbon. The results showed that: After different concentrations of $\mathrm{Pb}$ and atrazine compound applied into the soil, microbial biomass carbon content increased significantly in a short time, that generate a facilitating role on soil microbial biomass carbon. With the passage of cultured time, microbial biomass decreased.
\end{abstract}

Keywords-atrazine; $P b$; combined pollution; microbial biomass carbon.

\section{INTRODUCTION}

Chemical herbicides have been widely used in agricultural production currently, but the utilization rate is less than $30 \%$,most of them into the soil environment and pose a serious threat to soil. Soil microbial biomass carbon can be used as indicators of soil quality evaluation of Microbiology ${ }^{[1,2]}$ and predict the stability of soil system ${ }^{[3]}$, the number is affected by the ratio of carbon to nitrogen, fertilization, heavy metal pollution, land use patterns, pesticide pollution and many other factors. Small changes in microbial biomass pool, will have an important impact on the nutrient cycling and physicochemical properties of soil, causing the change of structure and function of soil. The effects of heavy metal pollution and pesticide pollution is the most significant. Research shows that pesticides and other organic pollutants can make the soil microbial biomass carbon decreased largely ${ }^{[4]}$.In recent years, in the soil environment have been carried many research on interaction between many kinds of organic pollutants (heavy metals) and inorganic pollutants ${ }^{[5-6]}$. $\mathrm{Hu}^{[7]}$ and Maliszewska ${ }^{[8]}$ study, compound pollution of heavy metals and organic have a remarkable composite effect on the effect of biological activity, soil enzyme activity and othe rbiological index, the strength of biological effects resulting from the combined effect is greater than the strength of biological effects producing independently; the study of Liu Wenxia ${ }^{[9]}$ show that, when $\mathrm{Pb}^{2+}$ and atrazine mixed in different proportion, $\mathrm{Pb}^{2+}$ in different concentration lead in the different concentration of atrazine in the rice.

In this research we choose two kinds of typical pollutant atrazine and $\mathrm{Pb}$ as the soil influence factor test, to explore its application to the soil in the short term effect on soil microbial biomass carbon change, aim to explore the combined effect and the interaction effect of complex pollution of lead and atrazine.

\section{MATERIALS AND METHODS}

\section{A. The soil tested}

Soil sampling locations for the Erros of wangzhuang (N36 $\left.38^{\prime}, \mathrm{E} 116^{\circ} 51^{\prime}\right)$, the surface soil sample collected by $0-20 \mathrm{~cm}$, a total of 12 selected sampling sites. After collected fresh soil sample, picking out plant residues, and divided them into two parts, a part of soil sample through in $2 \mathrm{~mm}$ sieve and mixed evenly, put in the $25{ }^{\circ} \mathrm{C}$ constant temperature incubator for cultivating experiment. The other part of soil samples by drying, grinding and sieving, for the determination of chemical properties of the soil.

\section{B. Reagents and instruments}

1) Main reagents: Atrazine (Shandong Qiaochang Chemical Co., Ltd., the content of effective components in $50 \%), \quad\left(\mathrm{CH}_{3} \mathrm{COO}\right)_{2} \mathrm{~Pb}, \quad \mathrm{~K}_{2} \mathrm{Cr}_{2} \mathrm{O}_{7}, \quad \mathrm{FeSO}_{4} \cdot 7 \mathrm{H}_{2} \mathrm{O}, \quad \mathrm{H}_{2} \mathrm{SO}_{4}$, adjacent coffee Rowling reagents were analytically pure. Solutions were prepared with distilled water.

2) Equipment: PHS-3D type acidity meter, AIM600 electro thermal digestion instrument, constant temperature incubator; spectrophotometer, reciprocating oscillating machine.

\section{Method}

Determination of the content of soil organic matter by potassium dichromate method, the determination of soil microbial biomass carbon "analysis by fumigation extraction volume".

\section{RESULTS AND ANALYSIS}

A. Soil microbial biomass carbon without pollution factor

Without any treatment of the original soil samples were incubated in the experiment, after first, 3, 5, 7, 14 and 28 days, soil microbial biomass carbon were determined. According to $60 \%$ of maximum field capacity calculation, 
weigh $27.72 \mathrm{~g}$ fresh soil (equivalent to $25.0 \mathrm{~g}$ dry soil).Fumigation and soil fumigation with $50 \mathrm{~mL} 0.5 \mathrm{~mol} / \mathrm{L}$ are not $\mathrm{K} 2 \mathrm{SO} 4$ solution extraction, and provided no soil matrix blank control, with the potassium dichromate oxidation microbial biomass carbon, the remainder of the potassium dichromate standard FeSO4 solution titrate to the endpoint, the FeSO4 solution volume consumed records. The organic carbon and microbial biomass carbon formula, the microbial biomass carbon in different sampling time as shown in table I.

TABle I. Does Not AdD Pollution Factor OF SoIl Microbial BIOMASS CARBON

\begin{tabular}{|c|c|c|c|c|c|c|}
\hline Treatments & 1 & 3 & 5 & 7 & 14 & 28 \\
\hline $\mathrm{CK}$ & 201.33 & 623.66 & 406.65 & 496.14 & 542.18 & 374.05 \\
\hline atrazine+Pb300 & 380.30 & 742.60 & 245.28 & 393.81 & 244.14 & 247.00 \\
\hline atrazine+Pb600 & 153.40 & 631.70 & 742.29 & 766.71 & 443.01 & 165.21 \\
\hline
\end{tabular}

B. Atrazine and $\mathrm{Pb}(300 \mathrm{mg} / \mathrm{kg})$ effect of combined pollution on soil microbial biomass carbon

The recommended dose of atrazine $(1.50 \mathrm{mg} / \mathrm{kg})$ and $\mathrm{Pb}$ $(300 \mathrm{mg} / \mathrm{kg})$ treatment of soil samples were incubated in the experiment, after first, 3, 5, 7, 14 and 28 days, respectively, for determination of soil microbial biomass carbon as shown in table 1.With the culture time $t$ as abscissa, microbial biomass carbon as ordinate, drawn into a column chart, trend of soil microbial biomass carbon with time, as shown in Fig.1

As shown in Figure 1, soil microbial biomass carbon in atrazine and $\mathrm{Pb}(300 \mathrm{mg} / \mathrm{kg})$ composite treatment period with incubation time, soil microbial biomass carbon content increased. In cultured for first days and third days, microbial biomass carbon and soil compared with the untreated soil increased by $88.9 \%$ and $19.1 \%$, respectively. At the third day of cultivation, soil microbial biomass carbon content reaches the highest point. Subsequently, soil microbial biomass carbon began to decline rapidly, and lower than the initial soil microbial biomass carbon. The maximum amplitude decreased in Fourteenth days, 55\% lower than the original soil. The incubation period of atrazine treated soil, the microbial biomass carbon was improved, the soil microbial biomass carbon is in "up down" trend. Therefore, as can be seen, in the application stage, combined pollution of atrazine and low concentration of $\mathrm{Pb}$ showed a significant effect on soil microbial biomass carbon, after showing inhibition.

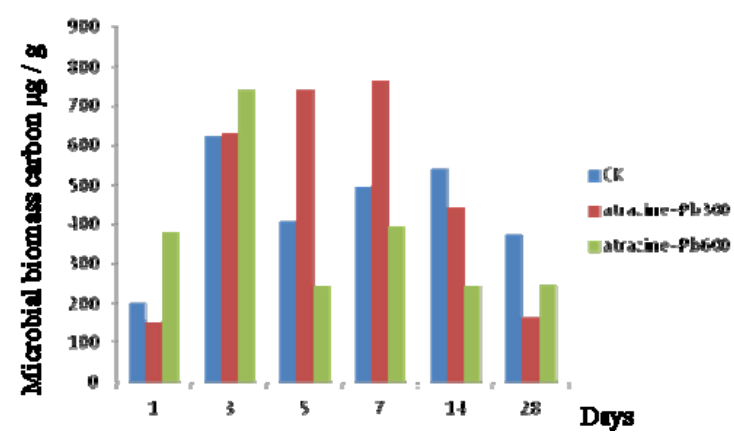

Figure 1. Atrazine and $\mathrm{Pb}$ microbial biomass carbon composite processing in soil

C. The effect of combined pollution on soil microbial biomass carbon

The experimental design of combined pollution of atrazine and $\mathrm{Pb}(600 \mathrm{mg} / \mathrm{kg})$ on soil microbial biomass carbon is consistent with the atrazine and $\mathrm{Pb}(300 \mathrm{mg} / \mathrm{kg})$. The experimental results are shown in table 1. Incubation time as abscissa and the value of the microbial biomass carbon as ordinate, the trend of soil microbial biomass carbon with time was shown in figure 1 As can be seen from Table 1, compared with the control group, microbial biomass carbon significantly improved after the recommended dose of atrazine and $\mathrm{Pb}(600 \mathrm{mg} / \mathrm{kg})$ were implied into the soil in the early stage of the incubation. The first seven days in the culture, microbial biomass carbon reached its highest point, which increased by $54.5 \%$ than the untreated soil. But in the first day, the microbial biomass in the experimental group was lower than the original soil. The first 14 days ,mirobial biomass carbon content decreased and lower than the content of the original soil .To the first 28 days , the microbial biomass carbon in the soil decreased by $55.8 \%$ than the original content .As shown in the Figure 1,after applying the composite of atrazine and $\mathrm{Pb}(300 \mathrm{mg} / \mathrm{kg})$ into the soil early in the culture, there was a significant stimulus on the microbial biomass carbon ,To the late stage of culture,soil microbial biomass carbon showed a dawnward trend , and compared with pre-treatment , and its content decreased a little as inhibition .therefore, it can be seen that atrazine and $\mathrm{Pb}(300 \mathrm{mg} / \mathrm{kg})$ combined pollution has the "inhibititedpromote-inhibited" effect on the soil microbial biomass carbon .

D. Comparison of different concentration of atrazine and $\mathrm{Pb}$ compound concentration on soil microbial biomass carbon

Analyse and compare similarities and differenties of the compound pollution of the atrazine and different concentrations $\mathrm{Pb}$ on the soil microbial biomass carbon. As can be seen from Figure 1, after the herbicide atrazine and different concentrations of $\mathrm{Pb}$ putted into the soil, microbial biomass carbon showes fluctuations over culture time, but the overall trend is promotion first and then suppression.The stimulating effect of two approaches on 
soil microbial biomass carbon may be due to the recommended dose of atrazine represents number of available carbon that part microbial population growth and $\mathrm{Pb}$ concentration within the tolerance range of microorganisms. Over time, heavy metals of herbicides were degradated by microbial, stimulate weakened, microbial biomass carbon returned to normal levels gradually.In the early stage of incubation, the microbial biomass carbon in the soil which is combined treated by atrazine and different concentrations of $\mathrm{Pb}$ begin showing an upward trend, but after atrazine and $\mathrm{Pb}(300 \mathrm{mg} / \mathrm{kg})$ soil microbial biomass carbon was significantly faster than atrazine and $\mathrm{Pb}(600 \mathrm{mg} / \mathrm{kg})$. To the three day, the former microbial biomass carbon is about 1.2 times than the latter. In the medium term, that is, within 4 to 7 days period, after atrazine and $\mathrm{Pb}(600 \mathrm{mg} / \mathrm{kg})$ treated, microbial biomass carbon of soil is continuing to increase, while the soil by atrazine and $\mathrm{Pb}(300 \mathrm{mg} / \mathrm{kg})$ treated began significantly reduced.

\section{THE CONCLUSION}

There exist differences in the treatment to the soil microbial biomass carbon using the atrazine and $\mathrm{Pb}$ with different concentrations, which presents as the role of activting first and suppression then. Its promoting role may be caused due to the substrate can provide soil microoganisms' growth the needed carbon and energy. The microoganisms matebolism is great, and the microbial biomass carbon relased has also increased. However, with the cultivation time extending, the degradation of the herbicides, other nutritient substances' consumption and the accumulations of the hazardous substance can reduce the microbial biomass carbon, and present the supression. A large number of researches suggested that residual time of the atrazine in the environment is relatively short, but comparing with the combined effects of heavy metals, its influences on the soil microorgnisms is long-termed and irreversible. Therefore, don't use them excessively and frequently for their low toxicity and short degradation cycle.

\section{V.ACKNOWLEDGEMENTS}

This work was supported by National Natural Science Foundation of China (41101530; 31270586), Science and Technology Development Plan of Shandong Province (2014GSF117029), International Cooperative Project of Shandong Province (2012GHZ21702)

\section{REFERENCES}

[1] Song Qiuhua, Li Fengmin, Liu Hongsheng,Wang Jun, Li Shiqing. Effect of Plastic film mulching on soil microbial biomass in spring wheat field in semi-arid loess area[J]. Chinese Journai of Applied Ecology, 2003,14(9):1512-1516.

[2] Xu Huaqin, Zhang Jiaen, Feng Lifang, Quan Guoming, Mao Danjuan, Qin Zhong.Effects ofdifferent land use patterns onm icrobialbiomass carbon and nitrogen in Guangdong Province[J]. Acta Ecologica Sinica,2009,29(8):4112-4118.

[3] Ren T Z, Grego S. Soil bioindicators in sustainable agriculture[J]. Scientia Agricultura Sinica, 2000, 33 (1): 68-75.

[4] Guo Xinghua, Qiao Yuhui, Zhao Jing, Sun Zhenjun. Indication and response of soil microbe to acetochlor[J]. Chinese Journal of EcoAgriculture, 2009, 17(5): 960-963

[5] Khan K S, Huang C Y. Effect of lead-zinc interaction on size of microbial biomass in red soil[J]. Pedosphere,1998,8(2):143-148.

[6] Gisi U. Synergistic interaction of fungicides inmixtures [J]. Phytopathology, 1996,86:1273-1279.

[7] $\mathrm{Hu}$ Zhubang, Wang Haizhen, Wu Jianjun, Xu Jianmin. Ecological effects of both single and combined pollution of $\mathrm{Cd}$ and bensulfuronmethyl on soil microorganisms.Journal of Zhejiang University (Agric. \&Life Sci.), 2005,31(2):151-156

[8] Maliszewska K B,Smreczak B. Habitat function of agricultural soils as affected by heavy metals and polycyclic aromatic hydrocarbons contamination[J]. Environment International, 2003, 28(8): 719 -728.

[9] Liu Wenxia, Guo Huawu, Li Bo, Shen Lianfeng. The influence of $\mathrm{Pb}^{2+}$ and butachlor interaction on growth and antioxidant enzyme activities of Lactuca Sativa L[J].Acta Scientiae Circumstantiae,2011,31(10):2282-2289 